\title{
Uji Mekanis Guide Vane dari Hasil Pengecoran Paduan Alumunium dan Tembaga
}

\author{
Chandra Buana $^{1 *}$, Jumadi Tangko ${ }^{1}$, Andi Afdhal Rasydiman'1 ${ }^{1}$, Ahmad Tamal S ${ }^{1}$ \\ ${ }^{1}$ Jurusan Teknik Mesin, Politeknik Negeri Ujung Pandang, Makassar 90245, Indonesia \\ *chandra_bhuana@poliupg.ac.id
}

\begin{abstract}
Hydroelectric power plant is a power plant that utilizes kinetic energy of water that turns a turbine that has been coupled with a generator to produce electricity. Guide vane is a major component of a water turbine that is used to direct the incoming water to the spiral case so that water can focus pressure on the runner blade or turbine blade. This study aims to determine the mechanical properties of the guide vane from aluminum and copper casting. The method used is the Brinnel (HB) method of mechanical hardness testing using aluminum and copper casting with various specimen comparisons, namely 1:2, 1:1, 2:1. The hardness value for each specimen will increase with increasing copper content in the specimen. Specimens with a ratio of 1:2 are not good for use in making guide vane because they have a low brinnel hardness value and are unstable in each part. Specimens with a ratio of 1:1 have a stable hardness value in each part and are good for use in making guide vane, besides the cost required is cheaper compared to specimens 2:1 because it has a value of copper content that is smaller than the specimen $2: 1$.
\end{abstract}

Keywords - Components; Guide vane, Brinnel Hardness, casting

\begin{abstract}
Abstrak- Pembangkit listrik tenaga air merupakan pembangkit listrik yang memanfaatkan energi kinetik air yang memutar turbin yang telah dikopel dengan generator untuk menghasilkan listrik. Guide vane merupakan suatu komponen utama pada turbin air yang diberfungsi untuk mengarahkan air yang masuk pada spiral case agar air dapat memusatkan tekanan pada runner blade atau sudu turbin. Penelitian ini bertujuan untuk mengetahui sifat mekanis guide vane hasil pengecoran alumunium dan tembaga.Metode yang digunakan adalah uji kekerasan mekanis metode Brinnel (HB) menggunakan pengecoran alumunium dan tembaga dengan berbagai macam perbandingan spesimen yaitu 1:2, 1:1, 2:1. Nilai kekerasan untuk setiap spesimen akan meningkat seiring dengan bertambahnya kandungan tembaga didalam spesimen tersebut. Spesimen dengan perbandingan 1:2 tidak baik untuk digunakan dalam pembuatan guide vane karena memilki nilai kekerasan brinnel yang rendah dan tidak stabil pada setiap bagiannya. Spesimen dengan perbandingan 1:1 memiliki nilai kekerasan yang stabil di setiap bagiannya dan baik untuk digunakan dalam pembuatan guide vane, selain itu biaya yang dibutuhkan lebih murah di bandingkan dengan spesimen 2:1 karena memiliki nilai kandungan tembaga yang lebih kecil dari spesimen $2: 1$.
\end{abstract}

Kata Kunci-Komponen; Guide vane, Brinnel Hardness, casting

\section{PENDAHULUAN}

Pembangkit listrik tenaga air merupakan pembangkit listrik yang memanfaatkan energi kinetik air yang memutar turbin yang telah dikopel dengan generator untuk menghasilkan listrik. Salah satu komponen utama dari suatu sistem PLTA adalah turbin yang mengubah energi kinetik menjadi energi mekanik berupa putaran sedangkan beberapa komponen bantu pada turbin yang diperlukan untuk mendapatkan efisiensi daya turbin yang besar, salah satunya adalah guide vane.

Guide vane merupakan suatu komponen utama pada turbin air yang diberfungsi untuk mengarahkan air yang masuk pada spiral case agar air dapat memusatkan tekanan pada runner blade atau sudu turbin, dimana bukaan dari guide vane di atur oleh governor. Guide vane dirancang untuk dapat menahan tegangan dan tumbukan air yang secara terus menerus, karena hal itu maka guide vane harus memiliki kekerasan material yang baik.. Dalam buku hydropower development (2004) halaman 61 [1] terdapat studi kasus yang melakukan penggantian guide vane yang terbuat dari baja yang telah rusak akibat korosi, Guide vane yang mengalami kerusakan akan mengakibatkan tekanan tidak seimbang pada spiral case, dan dapat merusak turbin itu sendiri .

Baja ringan merupakan baja karbon yang bersifat kaku dan kuat sehingga banyak digunakan untuk keperluan konstruksi. Baja ringan memiliki nilai kekerasan Brinell $130 \mathrm{BH}$ [2]. Baja ringan 
merupakan salah satu limbah praktek yang banyak ditemukan di Politeknik Negeri Ujung Pandang. Setiap tahun di Bengkel Mekanik Politeknik Negeri Ujung Pandang menghasilkan tidak sedikit limbah praktek berupa logam seperti stainless steel, tembaga, aluminium, seng, mauoun baja ringan . Namun limbah hasil praktek tersebut belum dimanfaatkan. Penanganan limbah tersebut biasanya dengan cara menjual ke pedagang pengumpul besi tua. Cara penanganan seperti itu, tidak menguntungkan karena harganya sangat murah. Oleh karena itu, dibutuhkan inovasi dan kreativitas dalam pemanfaatan limbah tersebut. Salah satu manfaat yang dapat diperoleh ialah mebuat gudie vane dari paduan alumunium dan tembaga. Berdasarkan penjelasan diatas maka penelitian ini dikhususkan untuk melakukan. uji meknais guide vane dari hasil pengecoran paduan alumunium dan tembaga.

\section{A. Material}

Material adalah sebuah masukan dalam produksi. Materialseringkali adalah bahan mentah yang belum diproses, tetapi kadang kala telah diproses sebelum digunakan untuk proses produksi lebih lanjut. Umumnya, dalam masyarakat teknologi maju, material adalah bahan konsumen yang belum selesai. Material yang digunakan dalam proses peleburan adalah logam.

Material logam memiliki nilai elektron bebas yang tinggi, dimana terdapat sejumlah besar elektron yang tidak terikat pada inti atom sehingga bisa bergerak bebas. Karena ikatan pada atom-atom logam sangat kuat maka hal ini mengakibatkan titik leleh dan titik didih logam sangat tinggi.Pada umumnya unsur logam mempunyai sifat fisis, antara lain:

1) Logam akan memantulkan sinar yang datang dengan panjang gelombang dan frekuensi yang sama sehingga logam terlihat lebih mengkilat. Contohnya, emas $(\mathrm{Au})$, perak $(\mathrm{Ag})$, besi $(\mathrm{Fe})$, dan seng $(\mathrm{Zn})$.

2) Logam dapat menghantarkan panas ketika dikenai sinar matahari, sehingga logam akan sangat panas (terbakar). Energi panas diteruskan oleh elektron sebagai akibat dari penambahan energi kinetik. Hal ini menyebabkan elektron bergerak lebih cepat. Energi panas ditransferkan melintasi logam yang diam melalui elektron yang bergerak.

3) Logam juga dapat menghantarkan listrik karena elektronnya terdelokalisasi bebas bergerak di seluruh bagian struktur atom. Tembaga $(\mathrm{Cu})$ sering dipakai dalam pembuatan kawat penghantar lisrik.

4) Meabilitas, yaitu kemampuan logam untuk ditempa atau diubah menjadi bentuk lembaran. Sifat ini digunakan oleh pandai besi untuk membuat sepatu kuda dari batangan logam. Gulungan baja (besi) penggiling menggunakan sifat ini saat mereka mengulung batangan baja menjadi lembaran tipis untuk pembuatan alat-alat rumah tangga. Hal ini karena kemampuan atom-atom logam untuk menggelimpang antara atom yang satu dengan atom yang lain menjadi posisi yang baru tanpa memutuskan ikatan logam.

5) Duktilitas yaitu kemampuan logam dirubah menjadi kawat dengan sifatnya yang mudah meregang jika ditarik. Tembaga $(\mathrm{Cu})$ dapat digunakan sebagai bahan baku pembuatan kawat.

6) Semua logam merupakan padatan pada suhu kamar dengan pengecualian raksa atau merkuri $(\mathrm{Hg})$ yang berupa cairan pada suhu kamar.

7) Semua logam bersifat keras, kecuali natrium ( $\mathrm{Na}$ ) dan kalium $(\mathrm{Ca})$, yang lunak dan dapat dipotong dengan pisau.

8) Umumnya logam memiliki kepadatan yang tinggi sehingga terasa berat jika dibawa.

9) Logam juga dapat menimbulkan suara yang nyaring jika dipukul, sehingga dapat digunakan dalam pembuatan bel atau lonceng.

10) Logam dapat ditarik magnet, sehingga logam disebut diamagnetik, misalnya besi ( $\mathrm{Fe})$.

\section{Aluminium}

Aluminium adalah senyawa logam yang terletak pada golongan III A, dengan lambang unsur Al dan memiliki nomer atom 13. Logam aluminium merupakan logam yang memiliki kelimpahan terbesar di bumi. Logam aluminium adalah logam yang mempunyai sifat ringan yang pemanfaatannya sangat luas. Selain ringan juga memiliki kelebihan lain seperti pengantar panas yang baik. 
Aluminium mempunyai beberapa sifat-sifat karakter fisis antara lain memiliki berat jenis sekitar $2,65-2,8 \mathrm{~kg} / \mathrm{dm}^{3}$, mempunyai daya hantar listrik dan panas yang baik, tahan terhadap korosi, dalam beberapa bahan, titik lebur $658^{\circ} \mathrm{C}$ dan susunan atom face centered cubic [3].

Penggunaan aluminium paduan di dunia industri pada saat ini terus berkembang pesat karena aluminium memiliki sifat mekanik seperti tahan korosi, bobot yang ringan, kekuatan dan kekerasan yang tinggi, serta mampu di daur ulang.Alumunium akan mengalami perbaikan bila dipadu dengan logam lain, seperti tembaga meninggikan kekerasan, magnesium kekuatan, silikon kesudian tuang dan logam pemadu lain adalah mangan, seng, nikel yang dapat mengakibatkan sifat yang dikehendaki dalam prosentase yang kecil [4].

Adapun sifat dasar dari aluminium (Al) murni adalah memiliki sifat mampu cor yang baik dan sifat mekanik yang jelek. Oleh karena itu dipergunakan aluminium paduan sebagai bahan baku pengecoran sebab sifat mekanisnya akan dapat diperbaiki dengan menambahkan unsur-unsur lain seperti tembaga $(\mathrm{Cu})$, silisium $(\mathrm{Si})$, mangan $(\mathrm{Mn})$, magnesium $(\mathrm{Mg})$ dan sebagainya [5]. Dari hasil pengujian pada aluminium paduan dengan cetakan pasir diperoleh harga tegangan tarik maksimal yaitu $93.8 \mathrm{~N} / \mathrm{mm} 2[6]$.

Tabel 1. Sifat mekanis alumunium [6]

\begin{tabular}{|l|l|}
\hline Titik lebur & $933,347 \mathrm{~K}, 660,32 \mathrm{C}, 1220,8^{\circ} \mathrm{F}$ \\
\hline Titik didih & $2792 \mathrm{~K}, 2519 \mathrm{C}, 4566^{\circ} \mathrm{F}$ \\
\hline Kekerasan skala Vickers & $167 \mathrm{Mpa}$ \\
\hline Kekerasan skala Brinnel & $245 \mathrm{Mpa}$ \\
\hline Kekerasan skala Mohs & 2,75 \\
\hline
\end{tabular}

\section{Tembaga}

Tembaga adalah logam yang ditemukan sebagai unsur atau berasosiasi dengan tembaga dan perak.Tembaga ini terdapat dalam jumlah yang relatif besar dan ditemukan selama pemisahan dari bijihnya (coal) pada elektrolisis dan pemurnian tembaga [7].

Tembaga mudah dicetak dan dibentuk, tahan terhadap korosi dan dikenal sebagai penghantar panas/listrik yang efisien. Oleh karena itu, tembaga sangat penting bagi manusia pada zaman dulu dan terus menjadi bahan pilihan untuk berbagai aplikasi rumah tangga, industri, dan teknologi tinggi hingga saat ini.

Tembaga sebagai unsur paduan alumunium dalam jumlah tertentu akan menambah kekuatan dan kekerasannya [8].

Tabel 2. Sifat mekanis tembaga [6]

\begin{tabular}{|l|l|}
\hline Titik didih & $2853 \mathrm{~K}, 2562 \mathrm{C}, 4643^{\circ} \mathrm{F}$ \\
\hline Titik lebur & $1357,77 \mathrm{~K}, 1038,62 \mathrm{C}, 1984,32^{\circ} \mathrm{F}$ \\
\hline Kekerasan skala Vickers & $369 \mathrm{Mpa}$ \\
\hline Kekerasan skala Brinnel & $874 \mathrm{Mpa}$ \\
\hline Kekerasan skala Mohs & 3,0 \\
\hline
\end{tabular}

\section{B. Teknik Pengecoran Logam}

Pengecoran daur ulang merupakan salah satu alternatif pengembangan industri pengecoran di Indonesia. Salah satu jenis logam bekas (daur ulang) yang banyak digunakan untuk pengecoran adalah jenis logam aluminium dan paduannya.

Pengecoran logam adalah menuangkan secara langsung logam cair yang didapat dari biji besi kedalam cetakan. Sedangkan coran adalah logam yang dicairkan, dituang kedalam cetakan, kemudian didinginkan dan membeku [9]. Pengecoran digunakan untuk membuat bagian mesin dengan bentuk yang kompleks Pengecoran digunakan untuk membentuk logam dalam kondisi panas sesuai dengan bentuk cetakan yang telah dibuat. Pengecoran dapat berupa material logam cair atau plastik yang bisa meleleh (termoplastik), juga material yang terlarut air misalnya beton atau gips, dan materi lain yang 
dapat menjadi cair atau pasta ketika dalam kondisi basah seperti tanah liat, dan lain-lain yang jika dalam kondisi kering akan berubah menjadi keras dalam cetakan, dan terbakar dalam perapian.

Pada proses cetakan permanen, cetakan biasanya di buat dari bahan logam, sehingga dapat digunakan berulang-ulang. Dengan demikian laju proses pengecoran lebih cepat dibanding dengan menggunakan cetakan sekali pakai, tetapi logam coran yang digunakan harus mempunyai titik lebur yang lebih rendah dari pada titik lebur logam cetakan.

\section{Uji Mekanis}

Sifat mekanik berhubungan dengan sifat elastis, plastis, Kekuatan dan Kekakuan, suatu material terhadap pembebanan yang diberikan (Sifat mekanis nano komposit HDPE [10]. Dimana Elastisitas adalah kemampuan suatu material untuk berdeformasi tanpa terjadinya perubahan (deformasi) yang permanen setelah tegangan dilepaskan. Untuk mengetahui sifat-sifat mekanik dari suatu material, maka yang harus dilakukan adalah melakukan pengujian terhadap material tersebut,uji mekanik yang bisa dilakukan untuk mengetahui sifat-sifat material yaitu uji kekerasan. Uji kekerasan merupakan pengujian yang paling efektif karena dengan pengujian ini, kita dapat dengan mudah mengetahui gambaaran sifat mekanis suatu material. Meskipun pengukuran hanya dilakukan pada suatu titik, atau daerah tertentu saja, nilai kekerasan cukup valid untuk menyatakan kekuatan suatu material. Dengan dengan melakukan uji keras, material dapat dengan mudah di golongkan sebagai material ulet atau getas. Pengujian kekerasan dalam dilakukan berbagai macam metode yaitu pengujian kekerasan dengan metode vickers, metode mikro hardness,metode rockwell, dan pengujian kekerasan metode Brinell.

Pengujian brinell adalah salah satu cara pengujian kekerasan yang paling banyak digunakan. Pada pengujian brinel digunakan bola baja yang dikeraskan sebagai indentor. Pengujian yang paling banyak dipakai adalah dengan menekankan penekan tertentu kepada benda uji dengan beban tertentu dan dengan mengukur ukuran bekas penekanan yang terbentuk diatasnya, cara ini dinamakan cara kekerasan dengan penekanan dengan Brinell Hardness Tester Kekerasan didefinisikan sebagai ketahanan suatu material terhadap indentasi / penetrasi permanen akibat beban dinamis atau statis.

Pengujian Brinell adalah salah satu cara pengujian kekerasan yang paling banyak digunakan. Indentor ditusukkan ke permukaan logam yang diuji dengan gaya tekan tertentu selama waktu tertentu pula (antara 10 sampai 30 detik). Karena penusukan (indentasi) itu maka pada permukaan logam tsb akan terjadi tapak tekan yang berbentuk tembereng bola. Kekerasan Brinell dapat dihitung menggunakan rumus

$$
\mathrm{BHN}=\frac{\mathrm{P}}{\Pi \mathrm{D} / 2 .\{\mathrm{D}-\sqrt{(\mathrm{D} 2-\mathrm{d} 2)\}} \ldots \ldots \ldots \ldots \ldots \ldots \ldots \ldots \ldots \ldots \ldots \ldots \ldots \ldots \ldots \ldots} 1.1
$$

Dimana :

(Dieter, 1987)

$$
\begin{aligned}
& \mathrm{P}=\text { gaya tekan }(\mathrm{kg}) \\
& \mathrm{D}=\text { diameter bola indentor }(\mathrm{mm}) \\
& \mathrm{d}=\text { diameter tapak tekan }(\mathrm{mm})
\end{aligned}
$$

Biasanya, pada pengujian kekerasan Brinell yang standar digunakan bola baja yang dikeraskan berdiameter $(10 \mathrm{~mm}$, gaya tekan $3000 \mathrm{~kg}$ (untuk pengujian kekerasan baja), atau 1000 atau $500 \mathrm{~kg}$ (untuk logam non ferrous, yang lebih lunak dengan lama penekanan 10 - 15 detik. Tetapi mengingat kekerasan bahan uji dan juga tebal bahan (supaya tidak terjadi indentasi yang terlalu dalam atau terlalu dangkal) boleh digunakan gaya tekan dan indentor dengan diameter yang berbeda asalkan selalu dipenuhi persyaratan $\mathrm{P} / \mathrm{D} 2=$ konstan. Dengan memenuhi persyararatan tersebut maka hasil pengukuran tidak akan berbeda banyak bila diuji dengan gaya tekan/diameter bola indentor yang berbeda. Harga konstanta ini untuk baja adalah 30, untuk tembaga/paduan tembaga 10 dan aluminium/paduan aluminium. Kekerasan Brineel juga dapat di hitung menggunakan nilai kekuatan Tarik suatu material dengan menggunakan rumus 
130 Chandra Buana, Jumadi Tangko, Andi Afdhal Rasydiman, Ahmad Tamal S. Uji Mekanis Guide Vane dari Hasil Pengecoran Paduan Alumunium dan Tembaga

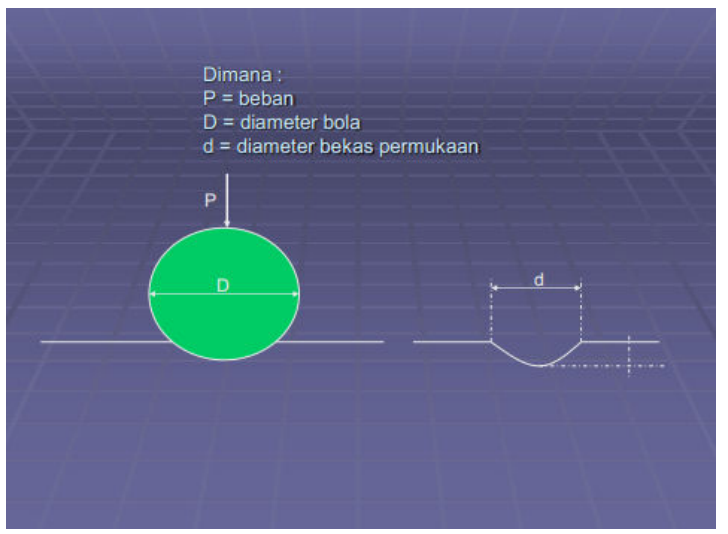

Gambar 1. Uji Kekerasan Brinnel [11]

Kekerasan Brinell Untuk pengujian logam yang sangat keras (di atas $500 \mathrm{BHN}$ ) bahan indentor dari bahan yang dikeraskan tidak cukup baik, karena indentor itu sendiri mungkin mulai terdeformasi, maka digunakan bola dari karbida tungsten, yang mampu mengukur sampai kekerasan sekitar 650 BHN.

\begin{tabular}{lccc}
\hline Jenis logam & $\begin{array}{c}\text { Kekuatan } \\
\text { Tarik } \\
(\mathrm{Mpa})\end{array}$ & $\begin{array}{c}\text { Keuletan } \\
(\%)\end{array}$ & $\begin{array}{c}\text { Kekerasan } \\
(\mathrm{BHN})\end{array}$ \\
\hline Besi dan baja & & $0-1$ & $100-150$ \\
Besi cor kelabu & $110-207$ & $0-1$ & 450 \\
Besi cor putih & 310 & $110-500$ \\
Baja & $276-2070$ & $12-15$ & $110-100$ \\
\hline Bukan Besi & & & \\
Aluminium & $83-310$ & $10-35$ & $30-100$ \\
Tembaga & $345-689$ & $5-10$ & $50-100$ \\
Magnesium & $83-345$ & $9-15$ & $30-60$ \\
Seng & $48-90$ & $2-10$ & $80-100$ \\
Titan & $552-1034$ & - & $158-266$ \\
Nikel & $414-1103$ & $15-40$ & $90-250$ \\
\hline
\end{tabular}

Gambar 2. Sifat logam pada pengecoran [12]

\begin{tabular}{ccc}
\hline $\begin{array}{c}\text { Lokasi Uji } \\
\text { Keras }\end{array}$ & Al-15\%Cu & Al-53\%Cu \\
\hline 1 & 50,1 & 74 \\
\hline 2 & 36,2 & 58,5 \\
\hline 3 & 75,9 & 60 \\
\hline 4 & 80,9 & 47,5 \\
\hline 5 & 73,6 & 48,6 \\
\hline 6 & 69,1 & 50,3 \\
\hline 7 & 63,7 & 50,4 \\
\hline 8 & 58,4 & 53,3 \\
\hline Rata-rata & 67,4 & 55,3 \\
\hline
\end{tabular}

Gambar 3. Hasil uji kekerasan HRB paduan alumunium dan tembaga [13]

\section{METODE PENELITIAN}

\section{A. Tempat dan Waktu Pelaksanaan}

Penelitian ini akan dilaksanakan di Jurusan Teknik Mesin Politeknik Negeri Ujung Pandang yaitu mulai pada bulan Mei 2019 sampai dengan bulan Agustus 2019. Pelaksanaan kegiatan diawali dengan perancangan guide vane, pembuatan dan pengujian, selanjutnya dilakukan pengambilan data uji mekanis. 


\section{B. Alat dan Bahan}

Peralatan yang digunakan dalam penelitian ini adalah sebagai berikut:

1) Tungku peleburan

2) Crucible

3) Cetakan logam

4) Pengukur temperatur jenis infrared

5) Tool seat

6) Alat pelindung panas

7) Affri Hardness Tester Series206 MX

8) Jangka sorong

9) Gerinda tangan

10) Infrared Thermometer FR-7866/ USB

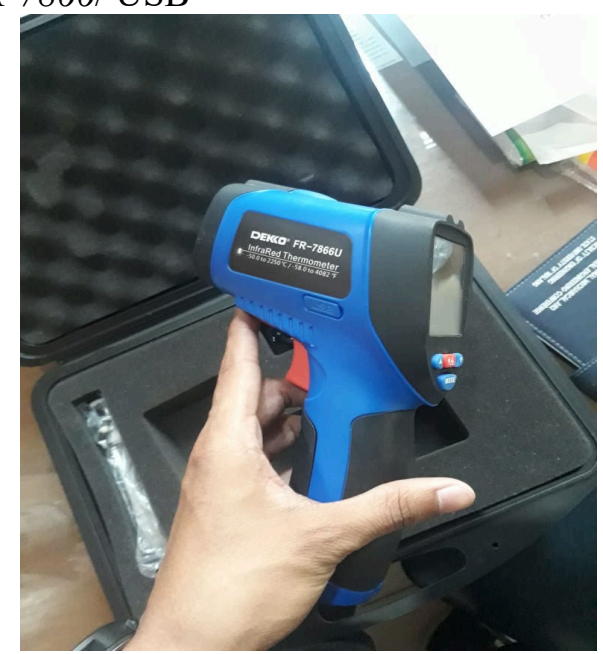

Gambar 4. Infrared Thermometer FR-7866/ USB

Spesifikasi :

- Range $:-50^{\circ} \mathrm{C}-2200^{\circ} \mathrm{C}$

- Response timen $:<250 \mathrm{~ms}$

- Power supply : $9 \mathrm{~V}$ battery

- Weight :290 g

- Optical resolution : $50: 1$

Sedangkan bahan yang digunakan dalam penelitian ini adalah

1) Plat Alumunium

2) Pipa tembaga 
132 Chandra Buana, Jumadi Tangko, Andi Afdhal Rasydiman, Ahmad Tamal S. Uji Mekanis Guide Vane dari Hasil Pengecoran Paduan Alumunium dan Tembaga

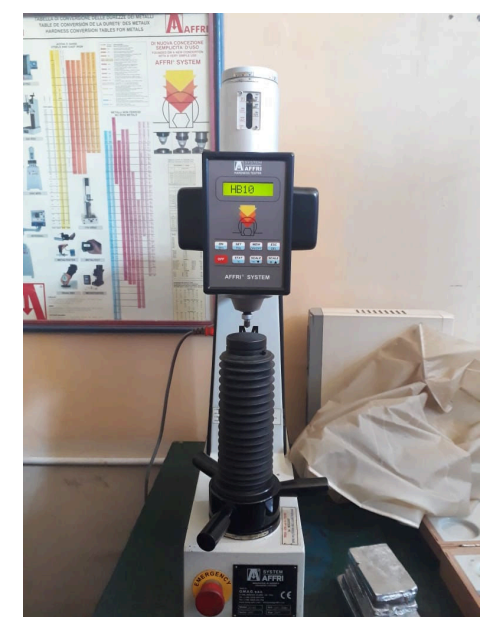

\section{Prosedur Penelitian}

Gambar 5. Affri Hardnes Tester Series206 MX

\section{Pembuatan Tungku peleburan dan cetakan Spesimen}

Jenis cetakan yang akan dibuat merupakan cetakan logam dengan sistem pemanasan gas elpiji . Pembuatan cetakan dimulai dari proses desain sampai dengan pembuatan dan perakitan cetakan. Proses desain meliputi pembuatan sketsa atau gambar dengan menggunakan softwere Autodesk. Adapun desain dari cetakan dan tungku peleburan dapat dilihat pada gambar 3.2 berikut:

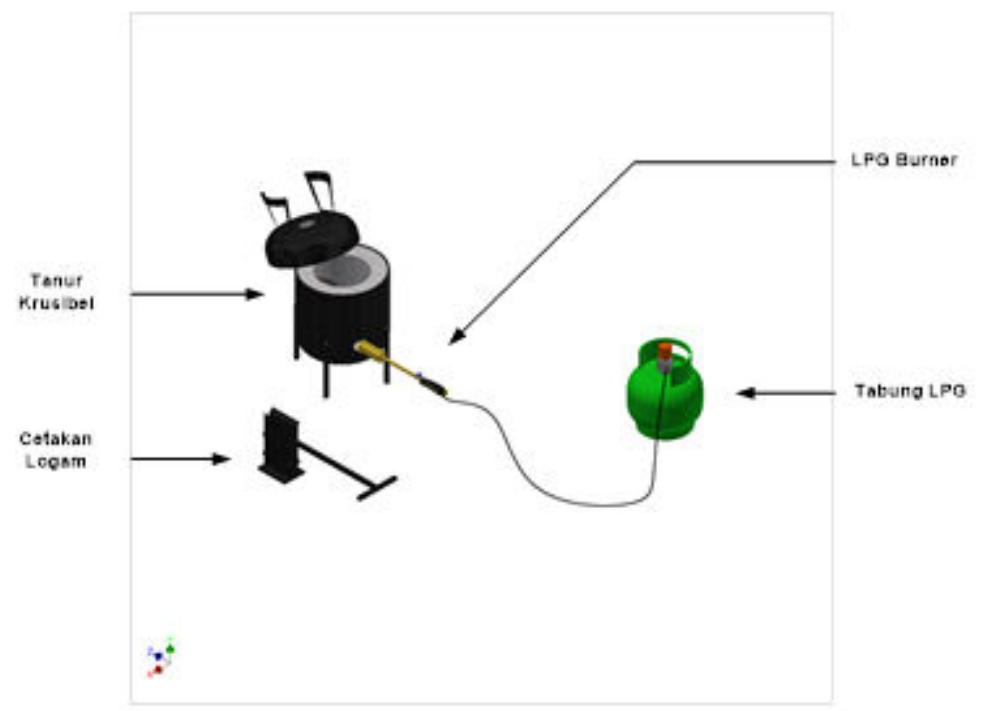

\section{Peleburan A...........ium dan Tembaga}

Gambar 6. Tungku Peleburan Logam

1) Peleburan logam dimulai dengan menyiapkan bahan alumunium dan tembaga sesuai dengan perbandingan yang diinginkan,

2) Mempersiapkan peralatan yang digunakan pada saat peleburan alumunium dan tembaga, dimulai dari pemanasan tungku menggunakan elpiji dan pemanasan tungku yang di letakkan pada bagian atas tungku peleburan.

3) Melakukan peleburan alumunium sampai mencapai titik leburnya yaitu $660,32{ }^{\circ} \mathrm{C}$ dan memasukkan pipa tembaga hingga $1055^{\circ} \mathrm{C}$

4) Apabila paduan aluminium tembaga lebur dan cetakan telah mencapai suhu sesuai dengan parameter yang ditentukan, selanjutnya yaitu proses penuangan cairan paduan ke dalam cetakan 
5) Proses terakhir adalah mengeluarkan paduan alumunium tembaga dari cetakan., dapat dilihat pada Gambar 3.2 berikut.

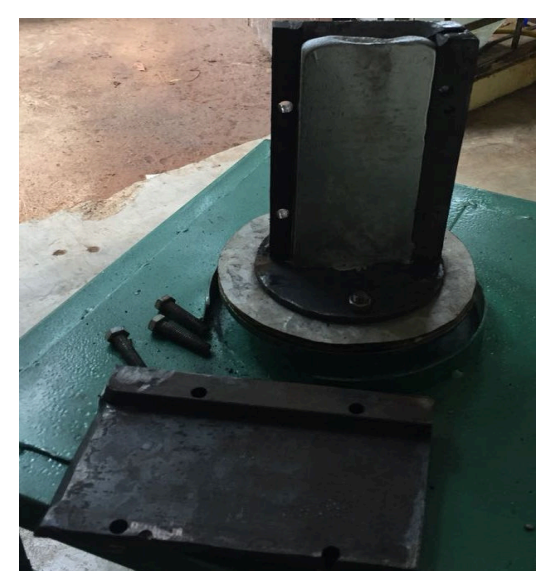

\section{Pembuatan Spesimen}

Gambar 7. Cetakan dan Spesimen Uji Kekerasan

Spesimen merupakan benda uji kekerasan brineel yang akan dibuat dengan perbandingan 1:2, 1:1 dan 2:1 ( $\mathrm{Cu}: \mathrm{Al})$

\section{Proses Pengujian}

Proses pengujian dilakukan dengan memperhalus permukaan spesimen terlebih dahulu kemudian menentukan titik titik pengujian pada masing-masing spesimen, setelah spesimen siap maka dilanjutkan dengan menyiapkan peralatan uji kekerasan dengan metode Brinell.langkah pengujian kekerasan sebagai berikut:

1) Memasang bola indentor $10 \mathrm{~mm}$.

2) Meletakkan spesimen yang akan diuji kekerasan Brinell.

3) Putar tuas untuk menaikkan plat sesuai dengan kebutuhan.

4) Menarik tuas sampai bola indentor pas mengenai spesimen uji, yang dapat dimonitor menggunakan layar dengan tanda arah panah.

5) Setelah 10 detik maka nilai kekerasan akan muncul pada layar alat uji kekerasan.

\section{Teknik Analisis Data}

Analisis data dilakukan untuk menentukan sifat mekanis dari guide vane berupa nilai dari kekerasan Brinell yang dilakukan pada uji kekerasan Brinnel. Nilai kekerasan Brinell kemudian akan di rata-ratakan untuk setiap bagian dan setiap perbandingannya.

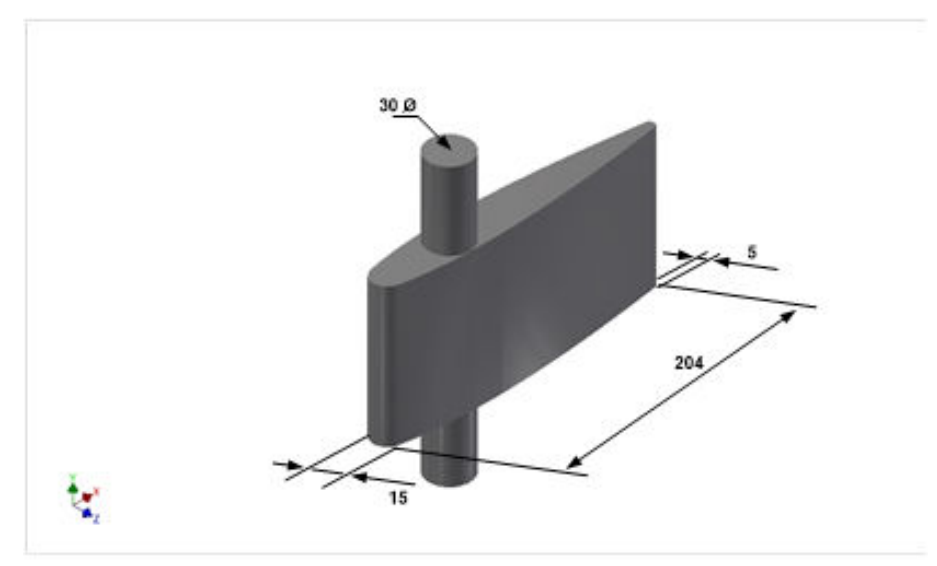

Gambar 8. Desain Guide Vane Pengecoran LImbah Praktek [14] 
134 Chandra Buana, Jumadi Tangko, Andi Afdhal Rasydiman, Ahmad Tamal S. Uji Mekanis Guide Vane dari Hasil Pengecoran Paduan Alumunium dan Tembaga

\section{HASIL DAN PEMBAHASAN}

Dalam penelitian kali ini metode yang digunakan untuk mendapatkan nilai kekerasan ialah dengan metode Brinnel (HB). Dalam proses pengujian ini penekanan di mulai dari bagian atas, kemudian tengah, dan yang terakhir bagian bawah. Masing-masing bagian dilakukan pengujian kekerasan sebanyak lima sisi. Spesimen yang digunakan seperti yang ditunjukkan pada gambar 4.1 berikut.

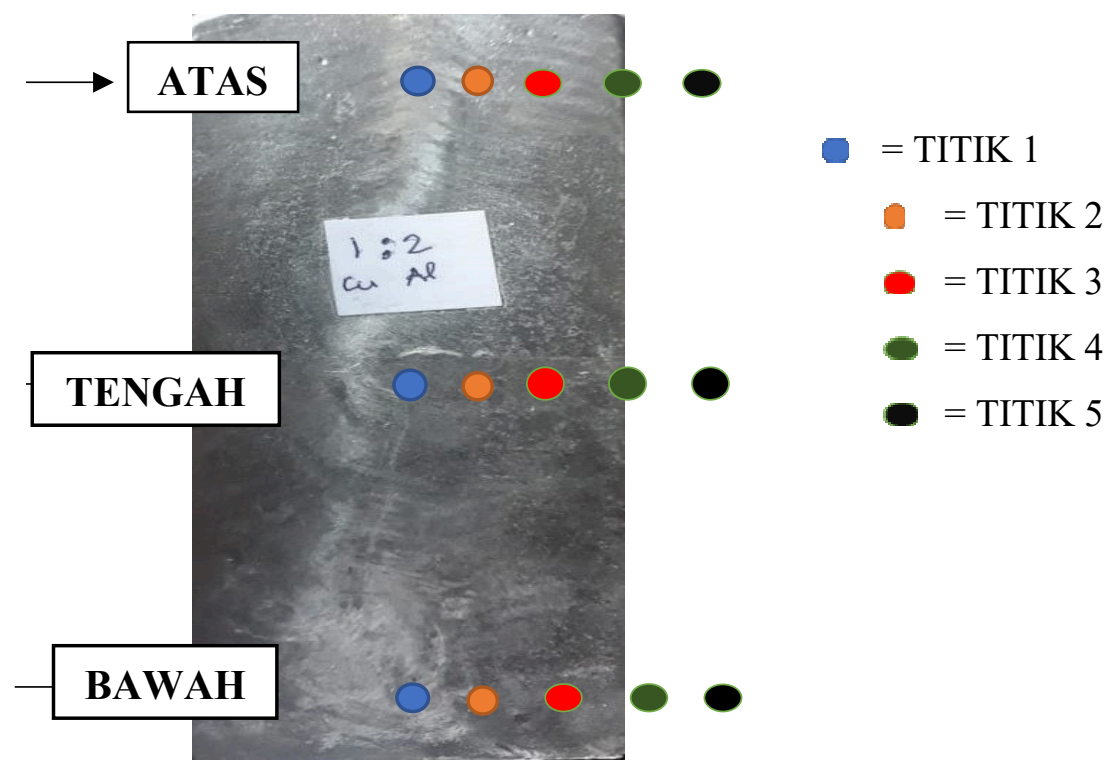

Gambar 9. Spesimen Uji kekerasan brinell

\section{A. Pengujian Nilai Kekerasan dengan Titik Uji}

Berdasarkan gambar 10 terlihat hubungan antara Titik Pengujian dengan Kekerasan Brinell (HB), dimana nilai kekerasan Brinell untuk setiap perbandingan memiliki nilai terendah pada bagian atas spesimen hal ini alumunium yang berada pada bagian atas spesimen memiliki kekerasan brinnel yang kecil dibandingkan dengan tembaga. Massa jenis alumunium yang rendah dari tembaga akan mengakibatkan alumunium berada pada bagian atas spesimen. Nilai kekersan brinnel terendah untuk setiap perbandingannya yaitu $118.76 \mathrm{HB}, 137.82 \mathrm{HB}, 151 \mathrm{HB}$, untuk perbandingan 1:2, 1:1, $2: 1$.

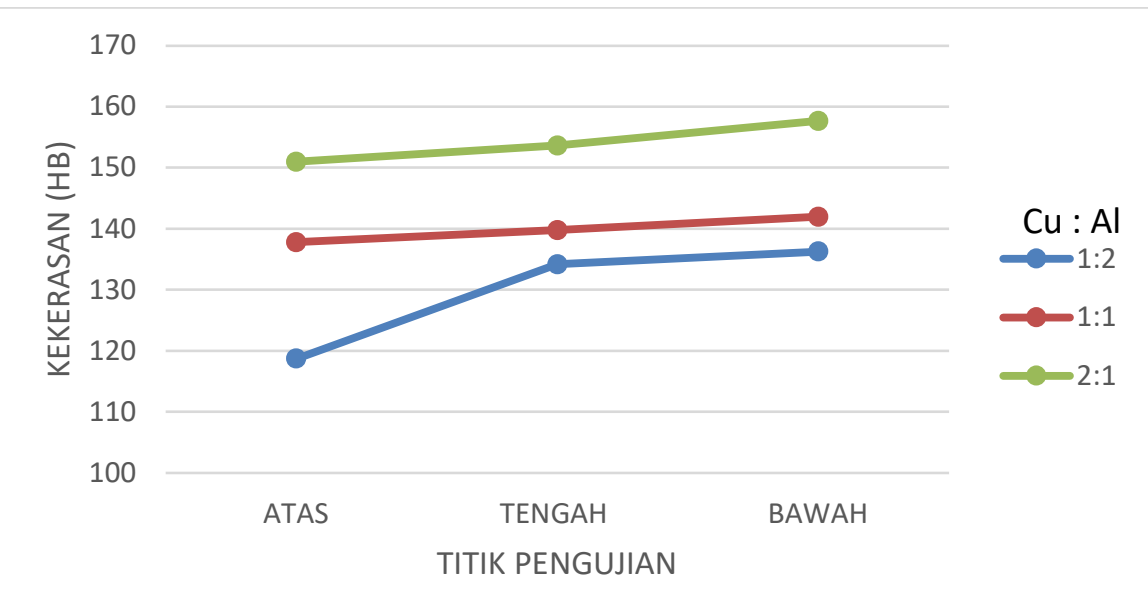

Gambar 10. Hubungan Antara Titik Pengujian dengan Kekerasan Brinell (HB) 


\section{B. Pengujian Nilai Kekerasan dengan Titik Uji}

Berdasarkan gambar 11 terlihat hubungan antara persentase kandungan tembaga dalam benda uji berbanding lurus dengan nilai kekerasan Brinell, dimana semakin besar kandungan tembaga dalam spesimen maka nilai kekerasan Brinell akan semakin besar begitupun sebaliknya. Pada spesimen nilai kekerasan brinnel tertinggi yaitu 154.1 HB dengan nilai kandungan tembaga sebesar $66.66 \%$ dan nilai kekerasan terendah yaitu $129.74 \mathrm{HB}$ dengan nilai kandungan tembaga sebesar $33.33 \%$.

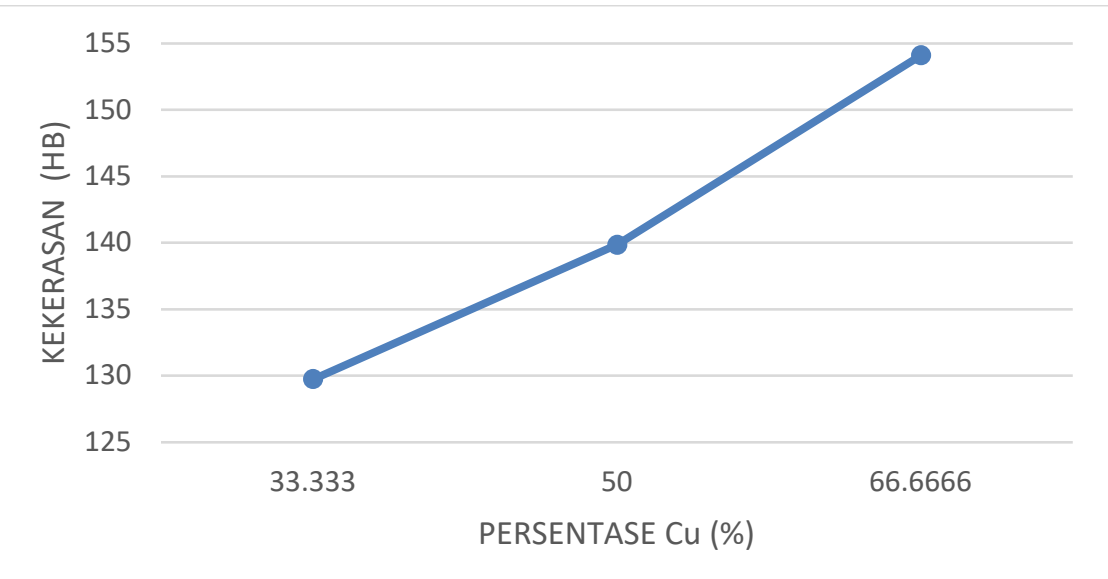

Gambar 11. Hubungan Antara Persentase Kandungan Tembaga (Cu) dengan Nilai Kekerasan Brinell (HB)

\section{KESIMPULAN}

\section{A. Kesimpulan}

Berdasarkan Analisis data dan pembahasan yang telah dilakukan pada bab sebelumnya, maka dapat disimpulkan bahwa,. Pengaruh penambahan tembaga pada spesimen akan meningkatkan nilai kekerasan spesimen. Spesimen dengan nilai kekerasan tertinggi yaitu spesimen dengan perbandingan 2:1,spesimen ini dapat digunakan sebagai material pembuatan guide vane, akan tetapi memerlukan biaya lebih karena memiliki kandungan tembaga yang besar di bandingkan dengan spesimen lain. Spesimen dengan perbandingan 1:2 tidak baik untuk digunakan dalam pembuatan guide vane karena memilki nilai kekerasan brinnel yang rendah dan tidak stabil pada setiap bagiannya. Spesimen dengan perbandingan 1:1 memiliki nilai kekerasan yang stabil di setiap bagiannya dan baik untuk digunakan dalam pembuatan guide vane, selain itu biaya yang dibutuhkan lebih murah di bandingkan dengan spesimen 2:1 karena memiliki nilai kandungan tembaga yang lebih kecil dari spesimen 2:1 . Akan tetapi dalam pembuatan guide vane banyak sifat mekanik yang harus diperhatikan selain kekerasan material seperti, uji tarik, uji impact, dan hal lainnya.

\section{B. Saran}

Berikut saran yang dapat dijadikan masukan bagi perusahaan dan pengembangan pengujian ini yaitu suatu perusahaan yang ingin membuat benda dengan nilai kekerasan yang baik maka dapat menggunakan tembaga sebagai paduannya, selain itu konstruksi tungku peleburan harus diperhatikan agar energi panas yang di gunakan dapat efisien.

\section{DAFTAR PUSTAKA}

[1] Headquarters, IMechE. 2004. Hydropower Developments-New Projects, Rehabilitation, and Power Recovery. London. UK.

[2] Engineering ToolBox, (2008). BHN - Brinell Hardness Number. Online Available at:https://www.engineeringtoolbox.com/bhn-brinell-hardnessnumberd_1365.html ( diakses pada 20 agustus 2019) 
136 Chandra Buana, Jumadi Tangko, Andi Afdhal Rasydiman, Ahmad Tamal S. Uji Mekanis Guide Vane dari Hasil Pengecoran Paduan Alumunium dan Tembaga

[3] F. Shifi S, dkk. 2014. Aluminium dan Senyawa-Senyawanya. Laboratorium Kimia Anorganik. Jurusan Kimia FMIPA. Universitas Negeri Semarang.

[4] Schonmetz, Alois., dan Gruber K. 1985. Pengetahuan Bahan Dalam Pengerjaan Logam. Bandung: Angkasa.

[5] Surdia, Tata., Saito, S., 1985, Pengetahuan Bahan Teknik, Cetakan Ke-3, PT. Padnya Paramita, Jakarta.

[6] Eva, Azis Nur. 2012. Analisis Sifat Fisis Dan Mekanis Aluminium Paduan Al-Si-Cu Dengan Menggunakan Cetakan Pasir. Jurusan Teknik Mesin Fakultas Teknik. Universitas Muhammadiyah Surakarta

[7] Hartati, R. D. 1996. Penentuan Tembaga dalam Contort Geokimia di daerah Bangko, Cara Graphite Furnace AAS. Jurnal Indo Kimia, 2(56), 215-220.

[8] Amstead, B.H., Myron L. Begemen dan Phillip F. Ostwald. 1997. Teknologi Mekanik Jilid I. Jakarta: Erlangga.

[9] Surdia, Tata, dan Chijiwa, K. 1976. Teknik Pengecoran Logam. Jakarta: PT. Pradnya Paramita.

[10] Ginting, Eva Marlina. 2016. Sifat Mekanis Nano Komposit Termoplastik Hdpe dengan Beberapa Bahan Pengisi. Medan: Unimed Pres.

[11] Suarsana, I KT. 2017. Ilmu Material Teknik. Program Studi Teknik Mesin. Fakultas Teknik. Universitas Udayana.

[12] Amstead B.H, Ostwalt P.F. 1995. Teknologi Mekanik. Jakarta: PT. Erlangga.

[13] Prayitno, Dody dan Muhammad Fatahillah Kawakibi Sodiqi. 2016. Studi Pengaruh Penambahan Tembaga Pada Porositas Almuminium.Prosiding Seminar Nasional XI Rekayasa Teknologi Industri dan Informasi 2016 Sekolah Tinggi Teknologi Nasional. 288-290. Yogyakarta : Sekolah Tinggi Teknologi Nasional.

[14] Subbarao, P.M.V. 2015. Design of Component of francis Tubine. Mechanical Enginering Department. Indian Institute of Technology Delhi. 